\title{
Facial Angle Profiles in Turkish Healthy Population
}

\author{
Sema Polat ${ }^{1}$, Ayse Gul Kabakci², Yigit Cevik ${ }^{3}$, Ahmet Hilmi Yucel ${ }^{4}$ \\ ${ }^{1}$ Department of Anatomy, Cukurova University, Balcali/Adana. ${ }^{2}$ Department of Anatomy, \\ Cukurova University, Balcali/Adana. ${ }^{3}$ Department of Anatomy, Cukurova University, Balcali \\ /Adana. ${ }^{4}$ Department of Anatomy, Cukurova University, Balcali/Adana.
}

\section{ABSTRACT}

\section{BACKGROUND}

The knowledge of the facial angles is essential for safe and accurate plastic surgery interventions. Facial angles are used as a reference value for comparison during diagnosis and treatment planning. Also, the facial angles will provide valuable data in evaluation of facial aesthetics. So, the aim of this study was to determine the ideal values of the facial angles in Turkish healthy adults.

\section{METHODS}

Two hundred and forty seven (129 females; 118 males) subjects aged between 18 and 25 years were included in this study. Frankfort horizontal plane was chosen to determine the angles related with face. Photographs were acquired using a Digital SLR Camera with fixed shooting values. (Canon EOS 80D; ISO $100 \mathrm{f} / 4.5$ ). In all the shoots, a printed scale with known dimensions was present. Acquired images were then transferred to a computer station. Measurements were made using Image J 1.52a with $1 / 100 \mathrm{~mm}$ sensitivity. Statistical analysis was done using SPSS Ver. 22.00. A $\mathrm{p}<0.05$ value was considered as significant. Student's T Test was used to determine the significance between gender, while Pearson Correlation analysis was done to evaluate the relation between gender.

\section{RESULTS}

Statistically significant difference was found between the genders and the frontonasal angle, the nasofrontal angle, the nasolabial angle, the chin neck angle, and the nasal projection. Also, the fronto nasal angle, chin neck angle, and nasal projection measurements were higher in males than in females, whereas the nasofrontal angle and nasolabial angle were lower in males than in females. Additionally, there was a significant, negative very low correlation between fronto-nasal angle $(-0.148)$, chinneck angle ( $\mathrm{r}=-0.179)$ and gender; a significant, negative and low correlation ( $\mathrm{r}=$ 0.243 ) between nasal projection and gender, a significant, positive and low correlation between nasolabial angle and gender ( $\mathrm{r}=0.259)$; and nasofrontal angle and gender $(r=0.388)$.

\section{CONCLUSIONS}

Facial angle values of healthy population provide important and useful knowledge in terms of comparison of abnormalities clinically, and data may be valuable for the representatives of clinical disciplines.

\section{KEY WORDS}

Nasofrontal Angle, Nasolabial Angle, Chin Neck Angle, and Nasal Projection
Corresponding Author:

Ayse Gul Kabakci,

Cukurova University, Faculty of Medicine,

Department of Anatomy,

Balcali/Adana.

E-mail: aysegull-88@hotmail.com

DOI: $10.14260 / \mathrm{jemds} / 2020 / 258$

Financial or Other Competing Interests: None.

How to Cite This Article:

Polat S, Kabakci AG, Cevik Y, et al. Facial angle profiles in Turkish healthy population. J. Evolution Med. Dent. Sci. 2020;9(08):1188-1191, 10.14260/jemds/2020/258

Submission 26-11-2019,

Peer Review 13-03-2020,

Acceptance 21-03-2020,

Published 06-04-2020.

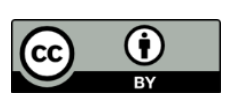




\section{BACKGROUND}

Physical appearance is a significant feature of the face. It is a subjective concept to describe an impressive face. The facial characteristic effects from ethnicity, age, gender, culture, and personality. Also, beauty concept changes from individuals to individual, race to race, ethnic groups. ${ }^{1}$ Facial harmony has been studied many periods by Greek philosophers, Egyptian sculptor, Renaissance artist, Michelangelo, and Leonardo Da Vinci. These studies provide benefits to facial aesthetics. It stated that the knowledge of the face ideal proportions by surgeons the surgical procedures will lead to use the correctly. ${ }^{2}$ Surgeons must assess the face as a whole to analyse facial proportion about choose the appropriate procedure and a good surgical outcome. ${ }^{2}$ Many methods have been used to determine facial features such as anthropometry and photogrammetry. ${ }^{3-5}$ Various angle measurements have been used to estimate the facial aesthetics. ${ }^{3}$ Nasolabial angle defines the inclination of the columella (distance between the base of nose and the nasal tip) regarding to the upper lip.6,7 The nasofrontal angle is a potentially important factor in the perception of facial profile attractiveness. The angle may be used to analyse the relationship between the glabellar region and the nasal dorsum in profile view. So, the magnitude of this angle will depend on the morphology of the glabellar region and the nasal bridge. Also, this angle is the most important measurement for soft tissue. To more accurately evaluate the nasal dorsal aesthetics, the nasofrontal angle may be separated into upper and lower component parts using a true horizontal line through nasion, allowing them to be assessed separately, as they vary independently.1,6 Nasal projection or nasomental angle is defined as nasal prominence angle ${ }^{3,8}$ and the most acceptable degree as aesthetically of nasal projection is between $20-30$ degrees. $^{3}$ Chin neck angle or cervicomental angle is described a line that tangential to the submental point from the chin to the subcervical region and another tangential to the neck at the subcervical region intersection the lowest point between the submental area and the neck. The reference value for chin neck angle is $120^{\circ}$ in males, $126^{\circ}$ in females. ${ }^{2}$ Frontonasal angle express that intersection of the nasion perpendicular with the forehand, the most prominent point in the midsagittal plane of the forehead, and the most concave point in the tissue overlying the area of the frontonasal suture. ${ }^{1}$

The purpose of this study was to evaluate the face angles and determine the reference values in healthy subjects.

\section{METHODS}

This is a cross sectional study carried out among 247 healthy adult subjects (129 females, 52.23\%; 118 males, 47.77\%) aged between 18-25 years from Cukurova University, Faculty of Medicine. All profile photographs were acquired using a Digital SLR Camera with fixed shooting values. (Canon EOS 80D; ISO $100 \mathrm{f} / 4.5$ ). Natural head positioning (approximating the Frankfort horizontal plane) was created by asking subjects to look straight ahead to a point at eye level on the wall. The photographic set-up consisted of a tripod. The tripod height was adapted to each subject's body height. In a standing position, each subject was asked to relax and was positioned on a Frankfort plane. The Frankfort horizontal plane was chosen to determine the angles related with face. This plane is described as reference plane. The lowest point of the orbita and the superior point of the external auditory meatus. ${ }^{9}$ Acquired images were then transferred to a computer. The measurement scale divided into degree and were made on the computer screen as digital and estimations were expressed as degree. Measurements were made using Image J 1.52a with $1 / 100 \mathrm{~mm}$ sensitivity. By using the measurement feature of the software (image J 1.52a with $1 / 100 \mathrm{~mm}$ sensitivity), first the distal point of the angle is chosen and, a line is drawn to the mid position of the angle measurement where the mouse button is hold. The second line is drawn by moving the mouse to the third point, and the angle measurement result are recorded.

\section{Procedure}

The study protocol was approved by the Ethics Committee of Cukurova University. All measurements were performed three times to participants by three different researchers (S.P., A.G.K., Y.C..), and the best measurement value was recorded. Moreover, all tests were performed at the same time in the morning and tests took about 30 minutes. The research study was explained to each participant prior to data collection and he or she gave informed consent. Additionally, inclusion criteria for healthy adult subjects were no history of having facial surgical operation, or any neurologic disease such as neuromuscular diseases. 255 subjects were included in this study at the beginning of the study. 5 subjects refused to attend to study later, although they meet the study criteria, and 3 subjects who cannot complete test are excluded from the study. Finally, 247 subjects participated to study.

\section{Statistical Analysis}

The SPSS 22.0 program was used for statistical analysis of the measurement results. In all statistical analyses; $p$ value under 0.05 was considered as statistically significant. Student's T Test was used to determine the significance between gender, while Pearson Correlation analysis was done to evaluate the relation between gender. From these measurements, means, standard deviations (SD), and minimum and maximum (min.max) values were calculated. The following parameters of five face angle dimensions were evaluated.

\section{Face Angle Measurements}

- Fronto-nasal angle is defined as the angle between the Trichion (hairline), Radix and Nasal tip. ${ }^{6}$

- Nasolabial angle is defined as angle between nasal tip, base of nose and anterior upper lip.6,7,10 Also, an inclination of the columella (distance between the base of nose and the nasal tip) regarding to the upper lip.6,7

- Naso-frontal angle is defined as the angle between the glabella, radix and dorsum of the nose. ${ }^{6,11-15}$

- Nasal projection is defined as the angle between the nasal tip, glabella (most prominent anterior point of the forehead) and alar base (the ala of the nose).3,6,15-17

- Chin-neck angle is defined as the angle between the inferior chin, reflex point and base of neck or by a line from the pronasale (the most prominent point of the apex 
nasi) and nasal tip to the most prominent point on the chin (Pogonion) as it intersects with the submental tangent. ${ }^{2,17}$

\section{RESULTS}

Two hundred forty seven (129 females; 118 males) subjects aged between 18 and 25 years were included in this study. Face angle measurements such as fronto nasal angle, nasofrontal angle, nasolabial angle, chin neck angle, and nasal projection performed on the Frankfort horizontal plane, were shown in Table 1. According to measurement results statistically significant difference was found between the genders in all parameters. Also, the fronto nasal angle, chin neck angle, and nasal projection measurements were higher in males than in females, whereas the nasofrontal angle and nasolabial angle were lower in males than in females. Additionally, there was a significant, negative very low correlation between fronto-nasal angle (-0.148), chin-neck angle $(r=-0.179)$ and gender. When analysed the relation between nasal projection and gender, there was a significant, negative and low correlation ( $\mathrm{r}=-0.243)$. Moreover, a significant, positive and low correlation was found between nasolabial angle and gender ( $\mathrm{r}=0.259)$; and nasofrontal angle and gender $(\mathrm{r}=0.388)$.

\begin{tabular}{|c|c|c|c|c|}
\hline $\begin{array}{c}\text { Parameters } \\
\text { (Degree “o”) }\end{array}$ & $\begin{array}{c}\text { Male (n=118) } \\
\text { Mean } \pm \text { SD } \\
\text { (Min - Max) }\end{array}$ & $\begin{array}{c}\text { Female } \\
\text { (n=129) } \\
\text { Mean } \pm \text { SD } \\
\text { (Min- Max) }\end{array}$ & $\mathbf{P}$ & $\begin{array}{c}\text { Total (n=247) } \\
\text { Mean } \pm \text { SD } \\
\text { (Min - Max) }\end{array}$ \\
\hline $\begin{array}{c}\text { Fronto-nasal } \\
\text { angle }\end{array}$ & $\begin{array}{c}150.59 \pm 8.18 \\
(127.07-170.73)\end{array}$ & $\begin{array}{c}148.25 \pm 7.54 \\
(129.19-175.24)\end{array}$ & 0.020 & $\begin{array}{c}149.37 \pm 7.92 \\
(127.07-175.24)\end{array}$ \\
\hline $\begin{array}{c}\text { Naso-frontal } \\
\text { angle }\end{array}$ & $\begin{array}{c}124.27 \pm 11.96 \\
(96.19-153.14)\end{array}$ & $\begin{array}{c}133.73 \pm 10.62 \\
(104.68-160.31)\end{array}$ & 0.0001 & $\begin{array}{c}129.21 \pm 12.21 \\
(96.19-160.31)\end{array}$ \\
\hline $\begin{array}{c}\text { Nasolabial angle } \\
100.04 \pm 15.61 \\
(40.91-129.19)\end{array}$ & $\begin{array}{c}108.04 \pm 14.39 \\
(75.61-146.69)\end{array}$ & 0.0001 & $\begin{array}{c}104.22 \pm 15.48 \\
(40.91-146.69)\end{array}$ \\
\hline $\begin{array}{c}\text { Chin-neck } \\
\text { angle }\end{array}$ & $\begin{array}{c}128.32 \pm 11.60 \\
(101.20-158.73)\end{array}$ & $\begin{array}{c}124.01 \pm 12.18 \\
(89.37-162.11)\end{array}$ & 0.005 & $\begin{array}{c}126.07 \pm 12.07 \\
(89.37-162.11)\end{array}$ \\
\hline Nasal projection & $\begin{array}{c}35.11 \pm 4.68 \\
(24.23-49.40)\end{array}$ & $\begin{array}{c}32.82 \pm 4.48 \\
(23.89-45.02)\end{array}$ & 0.0001 & $\begin{array}{c}33.92 \pm 4.71 \\
(23.89-49.40)\end{array}$ \\
\hline Table 1. The Angles Related with Face in Turkish Healthy Population \\
\hline $\begin{array}{c}\text { SD; standard deviation, Min; Minimum, Max; Maximum, n; number of participants, } \\
\text { p; Significant Student's t test, }\end{array}$
\end{tabular}

\section{DISCUSSION}

This study reported a range from $127.07^{\circ}$ to $175.24^{\circ}$ in frontonasal angle, $96.19^{\circ}$ to $160.31^{\circ}$ in nasofrontal angle, $40.91^{\circ}$ to $146.69^{\circ}$ in nasolabial angle, $89.37^{\circ}$ to $162.11^{\circ}$ in chin neck angle, and $23.89^{\circ}$ to $49.40^{\circ}$ in nasal projection. Nasolabial angle is defined as an inclination of the columella (distance between the base of nose and the nasal tip) regarding to the upper lip.6,7 Nasolabial angle's ideal value for nasolabial angle should be between $90^{\circ}$ and $120^{\circ}$. This angle may be affected some factors such as maxilla and maxillary incisors anteroposterior position, nasal tip rotation or vertical position upper lip soft tissue thickness ${ }^{6}$. This angle which depends on anteroposterior position or inclination of the anterior upper teeth can be change with orthodontic and or surgical treatment. ${ }^{3}$ In 110 Croatia population aged between 28.7 years, the nasolabial angle was reported as $109.39 \pm 7.84^{\circ}$ and $105.42 \pm 9.52^{\circ}$ in females and males, respectively. ${ }^{3}$ In 150 subjects aged between 18 and 32 years, the same angle was declared as $103.47 \pm 7.02^{\circ}$ and $105.27 \pm 7.61^{\circ}$ in males and females. Also, in pleasant profile group the nasolabial angle value was $104.37 \pm 7.25^{\circ}$, whereas in unpleasant profile group the corresponding value was $104.53 \pm 12.91$ degree $^{4}$. In a study performed by $\mathrm{Ahn}$ et al on 30 patients underwent septorhinoplasty aged between $31 \pm 9$ years, the nasolabial angle was found as $94.0 \pm 9.3^{\circ}$ and $107.2 \pm 9.6^{\circ}$ in preoperative and post-operative period, respectively. ${ }^{7}$ In Brazilian population, the same angle was measured in groups without tooth extraction $\left(95.1 \pm 14.1^{\circ}\right)$ and in groups with tooth extraction $\left(102.9 \pm 12.5^{\circ}\right) .{ }^{10}$ Hwang et al reported that the corresponding value was $93.45 \pm 8.49^{\circ}$ in anatomic point method and $62.25 \pm 9.99^{\circ}$ in tangent point method 40 Korean subjects with normal occlusion. ${ }^{1}$ In a study performed on 90 young females ( 46 participated to beauty Miss Korea Pageant; 44 young Korean females as control group) by Kim et al's, the corresponding value was reported as $98.85 \pm 11.68^{\circ}$ and 98.11 \pm 14.81 , respectively..$^{11}$ In present study, the nasolabial angle was found as $100.04 \pm 15.61^{\circ}$ and $108.04 \pm 14.39^{\circ}$ in males and females, respectively. Our result are similar to ideal nasolabial angle degree, Croatia and Portuguese population.

Nasofrontal angle is the anterior angle formed by drawing a line from nasion tangent to glabella, and another line tangent to the nasal dorsum, intersecting at nasion. The angle may be used to analyse the relationship between the glabellar region and the nasal dorsum in profile view. The magnitude of this angle will depend on the morphology of the glabellar region and the nasal bridge. ${ }^{6}$ Also, nasofrontal angle play an important role in rhinoplasty. The position of this angle can affect the shape of the nose and midfacial length in profile view. ${ }^{12}$ Nasofrontal angle is more important for achieving a pleasing facial line. In Naini et al study, the nasofrontal angle deviations of $148^{\circ}$ and $118^{\circ}$ and below were related with a greater proportion suggesting surgery. ${ }^{13}$ The corresponding value was reported as 127 degree in iraq dry bone (range from 95 to 178$) .12$

The results demonstrated that a nasofrontal angle of approximately 130 degrees is ideal, corresponding to a lower component of 60 degrees, with a range of 127 to 142 degrees deemed acceptable. Angles above or below this range are perceived as unattractive, and anything outside the range of 118 to 145 degrees is deemed very unattractive. Reduced nasofrontal angles, simulating a nasal hump deformity, of less than 115 degrees were deemed the least attractive. In terms of threshold values of desire for surgery, for all groups a threshold value of 148 degrees indicated a preference for surgery: for patients, the threshold value was 121 degrees or less; for lay people, the threshold value was 124 degrees or less; and similarly for clinicians, the threshold value was 118 degrees or less.12,13 Powell and Humphreys declared an ideal range between $115^{\circ}$ and $130^{\circ}$. Additionally, the reference values were $115^{\circ}$ in males $120^{\circ}$ in females.3,13 Lehocky reported the ideal value as $130^{\circ}$ in males $134^{\circ}$ in females. ${ }^{13}$ In Croatian population, nasofrontal angle reported as $136.38 \pm$ $6.71^{\circ}$ and $139.11 \pm 6.35$ in males and females, respectively. ${ }^{3}$ In a study performed by Ahn et al on 30 Chinese patients underwent septorhinoplasty aged between $31 \pm 9$ years $145.7 \pm 7.1$ degree. ${ }^{7}$ Our values $(124.27 \pm 11.96$ in males; $133.73 \pm 10.62$ in females) were between reference and desiring values of literature. However, our value are found different from values of Chinese population. 
Frontonasal angle is defined as the angle between the trichion, radix and nasal tip. ${ }^{6}$ Hwang et al reported that the frontonasal angle was $155.42 \pm 5.79^{\circ}$ in anatomic point method and $151.21 \pm 9.99^{\circ}$ in tangent point method 40 Korean subjects with normal occlusion ${ }^{1}$. In a study performed on 90 young females (46 participated to beauty Miss Korea Pageant; 44 young Korean females as control group) by Kim et al's, the corresponding value was reported as $144.01 \pm 8.28^{\circ}$ and $143.07 \pm 9.68^{\circ}$, respectively. ${ }^{11}$ The aesthetic value of nasal projection or nasomental angle was stated as $20^{\circ}-30^{\circ}$ by Lines. ${ }^{14}$ In a study performed by Miloševic et al, this angle was reported as $30^{\circ}$ and below in Clements's study, and between $23^{\circ}$ and 37 degree in Hinds and Kent's study. ${ }^{3}$ In healthy Croatian subjects, this angle was found as $29.5 \pm 2.5^{\circ}$ in males; $30.4 \pm 2.4^{\circ}$ in females. ${ }^{3}$ However, this dimension was measured as $35.11 \pm 4.68^{\circ}$ in males, $32.82 \pm 4.48$ in females, respectively. We found significant differences in the mean value of nasal projection of Lines' study, and Croatian population with our study; having lower than Turk. From this data, our results are more similar to Hinds and Kent's study.

Chin neck angle or mentocervical angle integrates the nasal tip analysis, neck position and chin projection. The ideal values ranges from $110^{\circ}$ to 120 degree. ${ }^{2}$ Haddad and Ghafari measured the chin neck angle as $84.16 \pm 9.4^{\circ}, 95.06 \pm 10.9^{\circ}$ and $78.26 \pm 9.36^{\circ}$ in white adult patients having Class I, Class 2 and Class 3 malocclusion groups, respectively. ${ }^{15}$ In summary, when comparing the literature findings with this study, we observe that there are differences between Brazilian and White adults (Americans).

The knowledge of the soft tissue angles is essential for safe and accurate plastic surgery interventions and used as a reference/standard value for comparison during diagnosis and treatment planning. Moreover, the differences of mean value of face angles between populations could be a result of factors impressing bone morphology including heredity, gender, race. Therefore, the observations presented in this study have defined anatomic parameters that need to be taken in consideration for performing safe surgical procedures such as orthodontics. As a result, we believe that the data obtained in this study can provide crucial information for facial morphometry and may help the surgeon for having a successful surgery and minimize the related problems.

\section{CONCLUSIONS}

Facial angle values obtained from our healthy Turkish population can be used as a reference data in comparison with subjects having same racial features. Also, gender differences were found in all measurements. In this context, these data may be an important finding. The measurement results indicated that the gender is one of the most important factors in causing angular differences. The Nasofrontal and the nasolabial angle were wider in females.

\section{REFERENCES}

[1] Hwang HS, Kim WS, McNamara JA Jr. A comparative study of two methods of quantifying the soft tissue profile. Angle Orthodontist 2000;70(3):200-7.

[2] Arroyoa HH, Olivetti IP, Lima LFR, et al. Clinical evaluation for chin augmentation: literature review and algorithm proposal. Brazilian Journal of Otorhinolaryngology 2016;82(5):596-601.

[3] Miloševic' SA, Lapter-Varga M, Šlaj M. Analysis of the soft tissue facial profile by means of angular measurements. European Journal of Orthodontics 2008;30(2):135-40.

[4] Fortes HNR, Guimarães TC, Belo IML, et al. Photometric analysis of esthetically pleasant and unpleasant facial profile. Dental Press J Orthod 2014;19(2):66-75.

[5] Karaca Ö, Gülcen B, Kuş MA, et al. Morphometric facial analysis of Turkish adults. Balıkesir Sağlık Bilimleri Dergisi 2012;1(1):7-12.

[6] Sarver D, Jacopson RS. The aesthetic dentofacial analysis. Clinics in Plastic Surgery 2007;34(3):369-94.

[7] Ahn TH, Zheng T, Kang HJ, et al. New technique in nasal tip plasty: sandwich technique using cartilage and septal bone complex. Ear Nose Throat J 2019:145561319881570.

[8] Clements BS. Nasal imbalance and the orthodontic patient. American Journal of Orthodontics 1969; 55(3):244-64.

[9] Hegde V. Significance of the Frankfort mandibular plane angle in prosthetic management of partially or completely edentulous patients with Class II malocclusions. The Journal of Indian Prosthodontic Society 2005;5(4):175-9.

[10] Freitas BV, Rodrigues VP, Rodrigues MF, et al. Soft tissue facial profile changes after orthodontic treatment with or without tooth extractions in Class I malocclusion patients: a comparative study. J Oral Biol Craniofac Res 2019;9(2):172-6.

[11] Kim SY, Bayome M, Park JH, et al. Evaluation of the facial dimensions of young adult women with a preferred facial appearance. The Korean Journal of Orthodontics 2015;45(5):253-60.

[12] Yas NK. Anthropometric study on the nasofrontal angle in human skulls. Fac Med Baghdad 2012;54(1):106-9.

[13] Naini FB, Cobourne MT, Garagiola U, et al. Nasofrontal angle and nasal dorsal aesthetics: a quantitative Investigation of idealized and normative values. Facial Plast Surg 2016;32(4):444-51.

[14] Lines PA, Lines RR, Lines CA. Profilemetrics and facial esthetics. American Journal of Orthodontics 1978;73(6):648-57.

[15] Haddad RV, Ghafari JG. Chin-throat anatomy: normal relations and changes following orthognathic surgery and growth modification. Angle Orthod 2017;87(5):696-702.

[16] Kashikar SV, Lakhkar BN. Assessment of fetal nasal bone length and nasofrontal angle in the second trimester in normal İndian pregnancies. Journal of Fetal Medicine 2014;1(3):137-41.

[17] Tollefson TT, Sykes JM. Computer imaging software for profile photograph analysis. Arch Facial Plast Surg 2007;9(2):113-9. 